\title{
Association of the glycaemic index and glycaemic load with colorectal cancer in the population of Córdoba (Argentina): results of a case-control study using a multilevel modelling approach
}

\author{
Eugenia Haluszka ${ }^{1}$, Valentina Luciana Dávila ${ }^{1}$, Laura Rosana Aballay ${ }^{1}$, Maria del Pilar Diaz ${ }^{1,2}$, \\ Alberto Rubén Osella ${ }^{3} \dagger$ and Camila Niclis ${ }^{1,2} *_{\dagger}$ \\ ${ }^{1}$ Escuela de Nutrición, Facultad de Ciencias Médicas, Universidad Nacional de Córdoba, Enrique Barros s/n, Ciudad \\ Universitaria, 5016 Córdoba, Argentina \\ ${ }^{2}$ Instituto de Investigaciones en Ciencias de la Salud, Consejo Nacional de Investigaciones Científicas y Técnicas - Universidad \\ Nacional de Córdoba, Haya de la Torre esq. Enfermera Gordillo, Ciudad Universitaria, 5016 Córdoba, Argentina \\ ${ }^{3}$ Laboratorio di Epidemiologia e Biostatistica, National Institute of Gastroenterology, "Saverio de Bellis" Research Hospital, \\ 70013 Castellana Grotte-Bari, Italy \\ (Submitted 19 July 2018 - Final revision received 7 December 2018 - Accepted 2 January 2019; First published online 14 February 2019)
}

\begin{abstract}
The glycaemic index (GI) and glycaemic load (GL) are involved in the aetiology of different diseases, and they could be related to the development of colorectal cancer (CRC). The aim of this study was to evaluate the association between the quality and quantity indicators of carbohydrates consumed by the population of Córdoba (Argentina) and the odds of developing CRC in 2008-2016 period. A case-control study was conducted with 492 participants (161/331 cases/controls), interviewed through a validated FFQ. Multilevel logistic regression models were used to assess the effect of GI, GL and the quantity or weekly intake of high-GI foods on CRC occurrence, following adjustment for individual/first-level covariates, and using level of urbanisation as the contextual variable. The models were stratified by sex. Participants in the highest $v$. lowest tertile of dietary GL and weekly intake of high-GI foods had increased odds of CRC presence in the entire sample (OR $1 \cdot 64,95 \%$ CI 1·16, $2 \cdot 34$ and OR 1.11, $95 \%$ CI 1.09, 1.14, respectively) and in women (OR 1.98, 95\% CI 1.24, 3.18 and OR 1.41, $95 \%$ CI 1.09 , $1 \cdot 83$, respectively). In men, the second tertile of GL and weekly intake of high-GI foods were associated with CRC (OR 1.44, 95\% CI 1.04, 1.99 and OR 1.48, $95 \%$ CI 1.32, 1.65, respectively). Also, GI was associated with CRC in women (highest $v$. lowest tertile OR $2 \cdot 12,95 \%$ CI 1.38 , $3 \cdot 27)$. In addition to the quantity and quality of carbohydrates intake, it is important to consider the frequency of consumption of high-GI foods in CRC prevention.
\end{abstract}

Key words: Glycaemic index: Glycaemic load: Colorectal cancer: Weekly intake of foods: Carbohydrates

Colorectal cancer (CRC) is the third most common cause of cancer deaths worldwide ${ }^{(1,2)}$ and the second most frequent cancer in Argentina ${ }^{(3)}$. Epidemiological studies have shown that some factors linked to glucose metabolism seem to be involved in the aetiology of several cancers ${ }^{(4-7)}$.

Intake of most carbohydrates $(\mathrm{CH})$ increases blood serum glucose and blood serum insulin but that depends on $\mathrm{CH}$ type and processing, the intake amount and the presence of other nutrients contained in the food. These variations are captured by the glycaemic index (GI), which is defined as the incremental area under the blood glucose response curve after eating $50 \mathrm{~g}$ of glucose or white bread. The GI is represented as a percentage of the response to the same $\mathrm{CH}$ amount from a standard food taken by the same subject ${ }^{(8)}$. The foods containing $\mathrm{CH}$ that are quickly digested, absorbed and metabolised are considered high-GI foods $(>70)$, whereas those slowly digested, absorbed and metabolised are considered low-GI foods $(<30)^{(9)}$. The GI measures $\mathrm{CH}$ quality, and its value is independent of the serving size or the amount of $\mathrm{CH}$ consumed. The glycaemic load (GL) is a measure that takes into account the $\mathrm{CH}$ amount in a portion of food and estimates the impact on the blood serum glucose; it is calculated by multiplying the GI by its total $\mathrm{CH}$ content and dividing the total by $100^{(10)}$.

Abbreviations: $\mathrm{CH}$, carbohydrate; CRC, colorectal cancer; GI, glycaemic index; GL, glycaemic load; IGF, insulin-like growth factor; MET, metabolic equivalent of task.

* Corresponding author: C. Niclis, fax +54 0351 4334021, email cniclis@fcm.unc.edu.ar

$\dagger$ These authors have contributed equally to this work. 
Dietary GL is the sum of the GL of all foods consumed in the diet $^{(10)}$. Per gram of $\mathrm{CH}$, foods with a high GI produce a higher peak in postprandial blood glucose and a greater overall blood glucose response during the first $2 \mathrm{~h}$ after consumption, unlike foods with a low $\mathrm{GI}^{(11,12)}$

It is suggested that a dietary intake with a high GI induces a greater insulin response, which contributes to keeping higher insulin blood levels and insulin-like growth factors (IGF) ${ }^{(13)}$. These analogues, particularly IGF-1, promote mitosis and cell proliferation and, at the same time, inhibit cell apoptosis, thereby producing uncontrolled cell growth. This may increase the risk of developing any type of cancer, including $\mathrm{CRC}^{(14)}$.

Evidence suggested that frequent eating is also involved in the aetiology of this cancer: it results in an increased secretion of bile acids into the gut lumen, and both dihydroxylation and deconjugation by colonic bacteria induce the conversion of these bile acids into secondary bile acids, which may have tumourigenic effects ${ }^{(15)}$. Since a frequent food intake can be harmful and could be related to $\mathrm{CRC}$, it is of interest to evaluate the CRC association with the frequent intake of high-GI food, which would also generate regular imbalances in the metabolism.

Several studies provide suggestive information about the relationship between the quality/quantity of dietary $\mathrm{CH}$ and CRC development ${ }^{(10,16-18)}$. A recent review has also uncovered consistent evidence that the risk of CRC is increased by a diet inducing high blood glucose levels. Particularly, a high GI was associated with a higher CRC occurrence in cohort and casecontrol studies ${ }^{(19)}$, though the weekly intake of high-GI foods was seldom object of scrutiny.

In Argentina, several epidemiological studies have been conducted to explore the relationship between eating habits and cancer; however, no specific information is yet available about dietary GI and the associated GL for this population related to CRC. We hypothesise that a high dietary GI and GL and/or a frequent dietary intake of high-GI foods could be associated with CRC development.

Thus, the aim of the current study was to examine the characteristics of diverse quality, frequency and quantity indicators of $\mathrm{CH}$ intake in the population of Córdoba (Argentina) and to estimate their association with CRC development in a case-control study.

\section{Methods}

\section{Study population}

A case-control study was performed from January 2008 to December 2016 in the framework of the Environmental Epidemiology of Cancer and other Chronic diseases group. Participants were residents of Córdoba, the second most populated Argentinian province $(3.3 \text { million people })^{(20)}$. To calculate the sample size, the annual incidence of CRC of Córdoba and the operative capacity for approximately 8 years were considered. To guarantee a power of $95 \%$ of the statistical tests to be used, at least two controls are identified for each case. A total of 492 participants aged 21-90 years were interviewed, including 161 subjects with incident histologically confirmed diagnosis of CRC
(ICD-10th edition, CIE10: C18-C20), with no previous diagnosis of cancer in other sites (cases) as well as 331 controls. The cases were identified by pathology departments or through oncologists' referrals in public and private healthcare institutions throughout the province of Córdoba; the controls were selected based on the geographical residence of cases.

Controls were chosen from the general population living in the same neighbourhoods and time periods as the cases, using a multistage sampling design as follows: numerous neighbourhood blocks were randomly selected; in each of these, four houses were visited until finding two to three controls per case frequency matched by sex and age ( \pm 5 years). On average, $10 \%$ of the people invited to take part in the interview refused to participate (response rate $92 \%$ in cases and $89 \%$ in controls).

All subjects were asked about their personal history of illness through a structured questionnaire to exclude those with a personal history of any neoplastic disease or any condition likely to result in long-term diet modification (e.g. diabetes, coeliac disease, renal insufficiency).

This study was conducted in accordance with the Declaration of Helsinki and the respective national laws ${ }^{(21)}$. All procedures involving human subjects were approved by the Ethical Committee of the Faculty of Medical Sciences, University of Córdoba. A written informed consent was provided by all subjects.

\section{Data collection}

All participants were interviewed by centrally trained and routinely supervised nutritionists. The interview focused on sociodemographic characteristics, occupational history, smoking habits, use of purge and non-steroidal anti-inflammatory drugs, self-reported anthropometric characteristics, physical activity, medical insurance, personal medical history and family history of cancer.

The socio-economic status was determined on the basis of aspects such as income, educational level and occupation of the household's main earner ${ }^{(22)}$. The physical activity was measured using the International Physical Activity Questionnaire ${ }^{(23)}$. The frequency, duration and intensity of physical activity were then expressed as the metabolic equivalent of tasks $\left(\right.$ MET) ${ }^{(24)}$. Subsequently, MET were categorised into low $(<600 \mathrm{MET})$, moderate (600-1500 MET) and high (>1500 MET) categories of physical activity intensity.

\section{Dietary assessment}

To assess dietary exposure, a validated FFQ of 127 items $^{(25)}$ was completed. Subjects were asked about their dietary intake over the 5 years before diagnosis (cases) or interview (controls). The FFQ was coupled with a validated photographic atlas based on standard serving sizes in Argentina ${ }^{(26)}$. The seasonal pattern of consumption for each vegetable or fruit was also taken into account by averaging the intake amount across a particular season throughout the year. The database of food composition used for daily intake quantification (energy content, ethanol, macro and micronutrients) includes a nutritional food composition table of Argentina ${ }^{(27)}$ and information from other biochemical determinations made at the local level ${ }^{(28)}$. 
To compute the average daily GI and GL, we assigned GI values to the seventy-two $\mathrm{CH}$-containing foods or food groups from the FFQ and differentiated their GI according to whether they were raw or cooked. These values were based on the recent international tables of $\mathrm{GI}$ and $\mathrm{GL}^{(11,29)}$, from which we chose the GI values of foods typically found on the Argentinian market. The GI was expressed as a percentage of the glycaemic response using white bread as a standard food with a GI of 100 . The average daily GI for a subject's diet was computed by summing the products of the GI value of each food, multiplying the amount of available $\mathrm{CH}$ and then dividing it by the total amount of available $\mathrm{CH}$ consumed per $\mathrm{d}$. The average daily GL (g) was calculated by adding up the products of the GI value of each food times the amount of available $\mathrm{CH}$ consumed per $\mathrm{d}$ divided by 100 . Each GL unit represents the equivalent of $1 \mathrm{~g}$ of $\mathrm{CH}$ from white bread.

\section{Statistical analysis}

Categorical variables and health status (with or without CRC) associations were evaluated using $\chi^{2}$ tests. A Student's $t$ test was performed to compare the mean values of nutrient intake between cases and controls. Missing data for each variable of interest were reported in the tables. To assess the association of quality, frequency and quantity of $\mathrm{CH}$ intake indicators with CRC, multilevel logistic regression models ${ }^{(30)}$ for the binary response (one for a CRC case, 0 for control) were estimated. A hierarchical structure in the data was assumed to capture the inter-individual variability and to assess individual-level variable effects such as the association between the exposure variables and the outcome. Subjects were included in a first level nested in a second level, that is, the extent of urbanisation defined as a scale aggregating subjects by the population size of their place of residence. This variable was defined according to three categories: $>1$ million inhabitants, 30000-1000 000 inhabitants and $<30000$ inhabitants. A total of four models were fitted including tertiles (based in controls) of the GI, the GL, high-GI food intake $(\mathrm{g} / \mathrm{d}$ ) or weekly intake of high-GI foods as exposure variables. Sex, age (years), BMI $(\mathrm{BMI}=$ weight $(\mathrm{kg}) /$ height $(\mathrm{m})^{2}$ ), socio-economic status (high, medium and low), energy intake $(\mathrm{kJ} / \mathrm{d})$, physical activity (low/moderate/high) and family history of CRC (yes/no) were included as adjusting variables at first level. The smallest reasonable number of covariables was included in the models. Some variables were not chosen since they were not associated with CRC (e.g. alcohol consumption data not shown). The models were also stratified by sex. OR and $95 \% \mathrm{CI}$ were obtained by adjusting for the mentioned covariates. The Stata ${ }^{\circledR} 15.1$ software $^{(31)}$ was used for data analysis, and $\alpha<0.05$ (two sided) was used as the criterion for assessing statistical significance.

\section{Results}

Table 1 shows a summary of the characteristics of CRC cases and controls. Ages ranged from 21 to 90 (mean age: 63 years), and $53 \%$ of participants were men. Cases had lower socioeconomic status than controls $(P<0.001)$, while overweight and obesity prevalence was similar in both groups (>60\%). Furthermore, the daily energy intake, the $\mathrm{CH}$ intake, as well as the GI and GL, were higher in cases than in controls $(P<0 \cdot 001)$. None of the subjects had low-GI food intake $(<30)$ (Table 1$)$.

Cases and controls showed a similar distribution of smoking habits and physical activity.

Mean values of GI and GL were 79.38 (SD 6.57) and 291.72 (SD 134.88), respectively, and they were higher in cases than in controls $(P<0.001)$ (Table 2$)$. Cases showed a higher weekly consumption of high-GI foods than controls (forty-two times per week - six times per $\mathrm{d}-v$. thirty-eight times per week - five times per $\mathrm{d}$, respectively, $P<0 \cdot 001$ ) (Table 2 ).

Table 3 illustrates the adjusted OR and the corresponding $95 \% \mathrm{CI}$ for $\mathrm{CH}$ intake indicators. Subjects in the third tertile of GL and weekly intake of high-GI foods had significantly higher odds for CRC than the reference (OR 1.64; $95 \%$ CI 1·16, 2.34; OR $1.11 ; 95 \%$ CI 1.09, 1.14, respectively). When stratified by sex, the highest category of GI and GL, and the weekly intake of high-GI foods showed a positive association with CRC in women (OR 2.12; $95 \%$ CI 1·38, 3.27; OR 1.98, $95 \%$ CI 1.24, $3 \cdot 18$ and OR $1.41,95 \%$ CI $1.09,1.83$, respectively). In men, the second tertile of GL and weekly intake of high-GI foods were associated with CRC presence (OR 1.44, 95\% CI 1.04, 1.99 and OR $1.48,95 \%$ CI $1.32,1.65$, respectively) (Table 3 ). The homogeneity test did not show differences by sex $(P>0.05$, data not shown).

The presence of a CRC family history was closely linked to CRC development, with OR of up to 2. Besides, the BMI showed a weak association with CRC in models including GL as covariate. On the other hand, the energy intake, socio-economic status, smoking habits and analgesic consumption did not show an association with CRC (data not shown).

\section{Discussion}

In this population-based case-control study, a high GL of dietary intake and an elevated weekly intake of high-GI foods were associated with the odds of developing CRC in the entire population. When stratified by sex, similar results were observed for those indicators and a high GI of dietary intake was associated with CRC in women.

Studies analysing the same indicators and their association with CRC in Argentina are not available; therefore, comparing results at the local level has been difficult. Mean values of dietary GI and GL in the present study were 79.38 (SD 6.57) and 291.72 (sD 134.88), respectively. These values are higher than those shown in other studies with similar population characteristics regarding sex and age (55\% men and mean age 56 years): 68.7 (SD 4) for GI and 165.7 (sD 38.9) for $\mathrm{GL}^{(16)}$. When comparing the results with different studies, it was taken into account that the GI tables used were those created by FosterPowell et al. ${ }^{(11)}$.

Cancer is a complex pathology, and its incidence and survival indexes are closely related to social, cultural and socioeconomic determinants of health ${ }^{(32)}$. Numerous studies have investigated the dietary GI and GL as potential risk factors in several cancers. Overall, results indicate a positive association 
Table 1. Characteristics of study participants according to their bio-socio-cultural data* (Numbers and percentages)

\begin{tabular}{|c|c|c|c|c|c|}
\hline & \multicolumn{2}{|c|}{ Cases $(n 161)$} & \multicolumn{2}{|c|}{ Controls ( $n$ 331) } & \multirow[b]{2}{*}{$P\left(x^{2}\right)$} \\
\hline & $n$ & $\%$ & $n$ & $\%$ & \\
\hline \multicolumn{6}{|l|}{ Socio-economic status } \\
\hline Low & 83 & 51.5 & 124 & 37.5 & $<0.001$ \\
\hline Moderate & 50 & $31 \cdot 1$ & 99 & 29.9 & \\
\hline High & 25 & $15 \cdot 5$ & 103 & $31 \cdot 1$ & \\
\hline Missing & 3 & 1.9 & 5 & 1.5 & \\
\hline \multicolumn{6}{|l|}{ BMI $\left(\mathrm{kg} / \mathrm{m}^{2}\right)$} \\
\hline Normal/underweight & 56 & $34 \cdot 8$ & 126 & $38 \cdot 1$ & 0.34 \\
\hline Overweight & 60 & $37 \cdot 3$ & 133 & $40 \cdot 2$ & \\
\hline Obese & 44 & $27 \cdot 3$ & 71 & 21.4 & \\
\hline Missing & 1 & 0.6 & 1 & 0.3 & \\
\hline \multicolumn{6}{|l|}{ Smoking habits } \\
\hline Ever smoker & 89 & $55 \cdot 3$ & 186 & $56 \cdot 2$ & 0.84 \\
\hline Never smoker & 72 & 44.7 & 145 & $43 \cdot 8$ & \\
\hline \multicolumn{6}{|l|}{ Physical activity (MET) } \\
\hline Low $(<600)$ & 78 & 48.5 & 175 & 52.9 & 0.33 \\
\hline Moderate $(600-1500)$ & 34 & $21 \cdot 1$ & 76 & $22 \cdot 9$ & \\
\hline High $(>1500)$ & 49 & $30 \cdot 4$ & 80 & 24.2 & \\
\hline \multicolumn{6}{|l|}{ Energy intake (kJ/d) } \\
\hline 1st tertile $(<99344.9)$ & 33 & 20.5 & 111 & 33.6 & $<0.001$ \\
\hline 2nd tertile (99344.9-14006.4) & 40 & 24.8 & 110 & $33 \cdot 2$ & \\
\hline 3rd tertile $(>14006 \cdot 4)$ & 88 & 54.7 & 110 & 33.2 & \\
\hline \multicolumn{6}{|l|}{$\mathrm{CH}$ intake $(\mathrm{g} / \mathrm{d})$} \\
\hline 1st tertile $(<263.54)$ & 33 & 20.5 & 110 & $33 \cdot 2$ & $<0.001$ \\
\hline 2nd tertile (263.54-380.59) & 47 & 29.2 & 111 & 33.6 & \\
\hline 3rd tertile $(>380.59)$ & 81 & $50 \cdot 3$ & 110 & $33 \cdot 2$ & \\
\hline \multicolumn{6}{|l|}{ Dietary GI† } \\
\hline Moderate GI (30-70) & 2 & 1.2 & 37 & $11 \cdot 2$ & $<0.001$ \\
\hline High GI (>70) & 159 & 98.8 & 294 & $88 \cdot 8$ & \\
\hline \multicolumn{6}{|l|}{ Dietary GL } \\
\hline 1st tertile $(<200 \cdot 37)$ & 30 & $18 \cdot 6$ & 111 & $33 \cdot 6$ & $<0.001$ \\
\hline 2nd tertile (200.37-298.66) & 44 & $27 \cdot 3$ & 110 & 33.2 & \\
\hline 3rd tertile (>298.66) & 87 & $54 \cdot 1$ & 110 & 33.2 & \\
\hline
\end{tabular}

MET, metabolic equivalent of task; $\mathrm{CH}$, carbohydrate; GI, glycaemic index; GL, glycaemic load.

* Case-control study of colorectal cancer in Córdoba, Argentina (2008-2016).

$\dagger$ Cut point based on Augustin et al. ${ }^{(9)}$ criterion.

Table 2. Mean glycaemic index (Gl), glycaemic load (GL) and food intake of different Gl foods ( $\mathrm{g} / \mathrm{d}$ and frequency of consumption)*

(Mean values and standard deviations)

\begin{tabular}{|c|c|c|c|c|c|}
\hline & \multicolumn{2}{|c|}{ Cases } & \multicolumn{2}{|c|}{ Controls } & \multirow[b]{2}{*}{$P(t$ test $)$} \\
\hline & Mean & SD & Mean & SD & \\
\hline GI & $80 \cdot 73$ & $5 \cdot 2$ & $78 \cdot 73$ & 6.9 & $<0.001$ \\
\hline GL & $332 \cdot 16$ & $146 \cdot 7$ & 272.05 & $124 \cdot 2$ & $<0.001$ \\
\hline Low-Gl foods $(\mathrm{g} / \mathrm{d}) \dagger$ & 89.58 & $76 \cdot 2$ & $110 \cdot 66$ & $97 \cdot 7$ & 0.9917 \\
\hline Moderate-Gl foods $(\mathrm{g} / \mathrm{d}) \dagger$ & 544.37 & $400 \cdot 1$ & $506 \cdot 65$ & 277.5 & 0.1123 \\
\hline High-Gl foods $(g / d) \dagger$ & 901.90 & 551.9 & $730 \cdot 56$ & $408 \cdot 1$ & $<0.001$ \\
\hline Weekly intake of low-Gl foods $\dagger$ & $9 \cdot 17$ & 7.4 & $10 \cdot 30$ & 7.9 & 0.9335 \\
\hline Weekly intake of high-Gl foods $†$ & $42 \cdot 33$ & $15 \cdot 9$ & 37.56 & $13 \cdot 3$ & $<0.001$ \\
\hline
\end{tabular}

* Case-control study of colorectal cancer in Córdoba, Argentina (2008-2016).

† Low-Gl foods: $\mathrm{Gl}<30$; moderate 30-70; high $>70^{(34)}$.

with some types of cancer ${ }^{(33-35)}$, and some of them indicate a positive association specifically with $\mathrm{CRC}^{(36-38)}$. A case-control study ${ }^{(36)}$ observed an inconsistent association between GL and $\mathrm{CRC}$; the results showed that compared to the first quartile of GL, the OR for the second through the upper quartiles were 1.38 (95\% CI 1.06, 1.80), 1.67 (95\% CI 1.30, 2.13) and $1.61(95 \%$ CI $1.25,2 \cdot 07)$, respectively $\left(P_{\text {trend }}<0 \cdot 0001\right)$. Similarly, a metaanalysis ${ }^{(38)}$ analysing twenty-four cohort studies and fifteen case-controls studies also found that dietary GI as GL were related to an increased risk of CRC; the summary results for GI and GL were 1.26 (95\% CI $1.11,1.44)$ and 1.18 (95\% CI 1.05 , $1 \cdot 34)$, respectively.

Furthermore, in a large population-based study, an association was found between high levels of blood glucose and the risk of CRC in men ${ }^{(39)}$; summary results for high $v$. low quartile of blood glucose were 1.72 (95\% CI 1.05, 2.84) for the entire 
Table 3. Association between quality and quantity indicators of carbohydrate intake and colorectal cancer ${ }^{\star}$ (Odds ratios and $95 \%$ confidence intervals)

\begin{tabular}{|c|c|c|c|c|c|c|c|}
\hline & \multirow[b]{2}{*}{ Cases/controls } & \multicolumn{2}{|c|}{ Entire sample } & \multicolumn{2}{|c|}{ Men } & \multicolumn{2}{|c|}{ Women } \\
\hline & & OR & $95 \% \mathrm{Cl} \dagger$ & OR & $95 \% \mathrm{Cl} \dagger$ & OR & $95 \% \mathrm{Cl} \dagger$ \\
\hline \multicolumn{8}{|l|}{ Gl } \\
\hline $\mathrm{T} 1$ & $41 / 111$ & \multicolumn{2}{|c|}{ - } & \multicolumn{2}{|c|}{ - } & \multicolumn{2}{|c|}{ - } \\
\hline T2 & $56 / 110$ & $1 \cdot 16$ & $0.80,1.70$ & 0.93 & $0.51,1.75$ & $2 \cdot 13$ & $1.59,2.86$ \\
\hline T3 & $64 / 110$ & 1.08 & $0.61,1.90$ & 1.01 & $0.38,2.69$ & $2 \cdot 12$ & $1 \cdot 38,3 \cdot 27$ \\
\hline \multicolumn{8}{|c|}{ Glycaemic load $\ddagger$} \\
\hline $\mathrm{T} 1$ & $30 / 111$ & \multicolumn{2}{|c|}{ - } & \multicolumn{2}{|c|}{-} & \multicolumn{2}{|c|}{-} \\
\hline T2 & $44 / 110$ & $1 \cdot 12$ & $0.74,1.71$ & 1.44 & $1.04,1.99$ & 0.60 & $0.28,1 \cdot 27$ \\
\hline T3 & $87 / 110$ & 1.64 & $1 \cdot 16,2 \cdot 34$ & 1.36 & $0.95,1.96$ & 1.98 & $1.24,3.18$ \\
\hline \multicolumn{8}{|c|}{ Intake of high-Gl foods $(\mathrm{g} / \mathrm{d}) \ddagger$} \\
\hline $\mathrm{T} 1$ & $33 / 110$ & \multicolumn{2}{|c|}{ - } & \multicolumn{2}{|c|}{-} & \multicolumn{2}{|c|}{ - } \\
\hline $\mathrm{T} 2$ & $47 / 111$ & 0.87 & $0.48,1.58$ & 1.00 & $0.51,1.96$ & 1.07 & $0.70,1.63$ \\
\hline T3 & $81 / 110$ & 1.01 & $0.84,1.58$ & 0.64 & $0.41,1.43$ & 1.46 & $0.50,4.29$ \\
\hline \multicolumn{8}{|c|}{ Intake of high-GI foods (times/week) $\ddagger$} \\
\hline $\mathrm{T} 1$ & $35 / 109$ & \multicolumn{2}{|c|}{ - } & \multicolumn{2}{|c|}{ - } & \multicolumn{2}{|c|}{-} \\
\hline T2 & $56 / 109$ & 1.21 & $0.91,1.60$ & 1.48 & $1.32,1.65$ & 1.08 & $0.40,2.60$ \\
\hline T3 & $69 / 109$ & $1 \cdot 11$ & $1.09,1 \cdot 14$ & 0.87 & $0.68,1.11$ & 1.41 & $1.09,1.83$ \\
\hline
\end{tabular}

T, tertile; GI, glycaemic index.

* Case-control study of colorectal cancer in Córdoba, Argentina (2008-2016).

† Sex (only for the entire sample), energy intake, BMI, socio-economic status, smoking habits (ever smoker-never smoker), analgesic consumption and family history of colorectal cancer were included as covariates at the first level and urbanisation at the second level.

‡ Cutpoints of tertiles based on controls distributions: GI: all: T1 77.25, T2 82.50; men: T1 78.29, T2 82.85; women: T1 75.29, T2 80.74. Glycaemic load: all: T1 200.38, T2 298.66; men: T1 213.98, T2 315.76; women: T1 194.03, T2 270.79. Intake of high-Gl foods (g/d): all: T1 494.5, T2 803.28; men: T1 512.95, T2 891.12; women: T1 458.12, T2 743.09. Intake of high-Gl foods (times/week): all: T1 31.12, T2 41.37; men: T1 31.37, T2 42.25; women: T1 31, T2 40.75.

population, meanwhile for men it was almost double the risk $2 \cdot 80$ (95\% CI $1 \cdot 37,5 \cdot 70)$. Instead, we found that women developed a higher CRC risk in comparison with men and, in some cases, an increase in CRC risk was observed only in women. Certainly, that study had specifically examined the relationship of the disease with a high level of blood glucose, which might be an effect of high-GI food intake, whereas we had assessed the food intake of the subjects. In a cohort of aging Caucasian adults ${ }^{(40)}$, GI and GL were not associated with the risk of adiposity-related cancers (CRC among them) combined or any of the site-specific cancers. However, higher consumption of low-GI foods, such as legumes, was associated with $36 \%$ lower risk of adiposity-related cancers combined. The protective impact of legumes was more pronounced among women, for whom legume consumption was associated with $43 \%$ lower risk of adiposity-related cancers. However, the protective effect of low-GI foods, particularly legumes, on cancer risk may be because these foods are rich in phytoestrogens, namely, isoflavones, which have weak oestrogenic properties and putative anti-oestrogenic effects ${ }^{(41)}$ that may reduce the risk of female adiposity-related cancers.

No associations of GI and GL with CRC were found in two meta-analyses ${ }^{(42,43)}$. The first one ${ }^{(42)}$ included fourteen cohort studies, and the second one, fourteen articles, exploring the relationship between GI, GL and CRC and adenomas. In the latter, there was a non-significant increased risk of CRC in the highest category of GI intake when all studies were combined; it was attributable to case-control study results and was subject to a marked heterogeneity. Other studies ${ }^{(44,45)}$ showed no associations of the indicators with CRC. Bao et al. ${ }^{(44)}$ had specifically studied the intake of those foods that increase the area under the insulin response curve and they found no relation with CRC. Furthermore, Flood et al. ${ }^{(45)}$ had found that GL, though not significantly associated with the risk of adenoma in women, had a significant inverse association with distal adenomas in men ${ }^{(45)}$.

On the other hand, in an extensive review Turati et al. ${ }^{(17)}$ found an increased risk of CRC with higher dietary GI (summary results 1.16, $95 \%$ CI $1.07,1.25)$. Besides, another review reported that, in contrast with the results obtained in this study, a high dietary GI, but not GL, was significantly and consistently associated with increased CRC risk in both cohort and casecontrol studies ${ }^{(19)}$. More recently, the dietary GI was positively associated with CRC risk $\left(\mathrm{OR}_{\text {quartile }} 4\right.$ v. 1 3 3.10; $95 \%$ CI $2 \cdot 51$, $3 \cdot 85$ ), but no evidence supported dietary GL intake as related to an increased risk of CRC in a Chinese population ${ }^{(16)}$.

Previous results from our study showed that the two patterns containing high-GI foods increased the risk of CRC development. A higher adherence to the 'southern cone' pattern (with a combination of starchy vegetables, red meat and wine intake) increases the odds by $50 \%$ (OR 1.5; $95 \%$ CI 1.0, 2.2), and the highest tertile of adherence to the 'high-sugar drink' pattern (with predominance of soda and juice intake) almost quadrupled the odds (OR 3.8; $95 \%$ CI 2.0, 7.1) compared with the first tertile ${ }^{(46)}$

Wang et $a l .{ }^{(47)}$ identified CRC as being associated with sugar and sugary drink intake (both of them with GI values higher than 70) in smoking men with no usual alcohol intake. In this study, the weekly intake of high-GI foods was significantly associated with the disease; however, no association was found with the average daily consumption of those foods.

In this study, a higher weekly intake of high-GI foods was significantly associated with the disease; however, no association was found with $\mathrm{g} / \mathrm{d}$ intake of high-GI foods. To date, the authors did not find other works examining the weekly intake of high-GI foods as an indicator of the quality/quantity of $\mathrm{CH}$ 
intake. A meta-analysis ${ }^{(15)}$ from 2014, which included fifteen studies, explored the association between eating frequency of all kind of foods and the risk of CRC; they found a modest evidence of an increased risk of CRC in case-control studies. One of the plausible physiological mechanisms to support the relationship between eating frequency and risk of CRC involves bile acids. It has been suggested that eating frequently results in an increased secretion of bile acids into the gut lumen and that dehydroxylation and deconjugation by colonic bacteria induce these bile acids to convert into secondary bile acids, which may have tumourigenic effects ${ }^{(48,49)}$. However, prospective studies suggest an inverse association between eating frequency and CRC risk, with evidence of effect modification by diet composition $^{(50)}$. People spend most of their lives in the postprandial state since the true fasting state occurs only in the last $2 \mathrm{~h}$ of a regular night sleep ${ }^{(51)}$; therefore, quality of food consumed will be key in the effect on health. Currently most of the foods consumed frequently are ultra-processed products ${ }^{(52,53)}$, which are mainly foods of poor quality (e.g. higher in $\mathrm{CH}$ of elevated GI and GL as well as low in dietary fibre and energy dense $)^{(54)}$. The main hypothesised mechanisms for GI and GL and their association with CRC are related to hyperinsulinaemia and insulin resistance, given that insulin acts as a growth factor and increases the bioavailability and bioactivity of IGF, such as IGF-1, by enhancing their synthesis and by decreasing their binding proteins. IGF-1 can promote tumour development by inhibiting apoptosis, thus stimulating cell proliferation and sexsteroid synthesis ${ }^{(9)}$. Higher-GI foods induce larger blood glucose fluctuations over the day than lower-GI foods. A frequent consumption of high-GI foods would imply a constant exposure to hyperinsulinaemia and its deleterious metabolic effect.

Besides, a systematic review ${ }^{(55)}$ identified several observational studies that reported the relevance of dietary GI/GL, fibre or whole-grain intake for chronic low-grade inflammation. The evidence from thirty-one intervention studies do not report a benefit of increasing fibre or whole-grain intake for low-grade inflammation, whereas several intervention studies do support a potential role of dietary $\mathrm{GI}$ or $\mathrm{GL}^{(56-59)}$. The mechanism whereby high-GI food intake may contribute to both acute and chronic low-grade inflammation and, in turn, promote the CRC development, is through oxidative stress ${ }^{(60)}$. The excessive postprandial blood glucose excursions are considered to yield nitric oxide, which in turn combines with superoxide to produce peroxynitrite - a potent long-lived pro-oxidant molecule ${ }^{(61)}$

Some methodological issues concerning case-control studies need to be considered. These include information bias related to the knowledge of disease status or 'recall bias' ${ }^{,(62)}$ - characterised by a propensity of cases to overestimate their exposure in the past - and selection bias.

To avoid bias due to confounding, we used a detailed procedure manual and considered all known confounding factors in the design of the study. Moreover, our interviewers were trained and the data collection was standardised as much as possible. The participation rate in cases was higher than in controls (92 and 89\%, respectively), given that the oncologists put cases on notice about the visit of members of our team for an interview. Although interviewers visited controls at their homes without previous notification, presenting their identification credentials as members of a research team facilitated their acceptance. The control sample seems to be representative of the Argentinean population. For instance, the prevalence of obesity (21.75\%) and of smoking habit (21\%) in controls was similar to that reported for the adult population of Argentina $(20 \cdot 8 \text { and } 25 \cdot 1 \% \text {, respectively })^{(63)}$.

FFQ may be prone to error; however, the reproducibility of the FFQ used has been accurately tested for epidemiological cancer studies $^{(26)}$. Previous studies about the validity of the results derived from case-control studies conducted by the research group were satisfactory ${ }^{(64,65)}$. Sensibility analysis regarding confounding, selection bias and information bias have also shown reasonably good results. The data showed acceptable correlations between FFQ and 24-h dietary recalls, suggesting that dietary intake is generally well measured ${ }^{(26)}$. This case-control study also benefits from using populationbased rather than hospital-based data, thus avoiding Berkson's bias (where hospital controls might not represent the prevalence of exposure in the community where cases come from). Controls came from the same geographical 'catchment area' as the cases and both, cases and controls, share mostly the same interview setting (the home). All of these procedures contribute to minimising both selection and information biases.

Finally, estimates may not accurately reflect the glycaemic effects of mixed dishes and prepared foods because GI measures the value of each food individually, and in the case of mixed meals it would be necessary to know how they were prepared and whether they were combined with other types of food.

In conclusion, this study provides evidence that a high GL and an elevated weekly intake of high-GI foods increase the risk of $\mathrm{CRC}$ in the population under study.

Taking this as a starting point, we postulated the need to promote a low-GI and -GL diet. This can be followed by reducing the quantity and the weekly intake of foods rich in simple $\mathrm{CH}$ and refined flours, such as honey, cooked vegetables, baked goods, non-whole grains, candies, among others and using strategies of food preparation and appropriate food combinations.

Epidemiological studies are designed to sample subjects from a particular population, so that the study population is representative of the target population. Once the nature and order of magnitude of an effect are established by maximising validity, the generalisation to other groups is simpler ${ }^{(66)}$. This is particularly important in our study, as it has been conducted in a scenario where the known and well-recognised risk factors for this pathology are widely and strongly distributed in the entire Argentine population.

\section{Acknowledgements}

The authors acknowledge the National Scientific and Technical Research Council for C. N.'s fellowship, the National Interuniversity Council for E. H.'s fellowship, the Córdoba Tumour Registry and the physicians who contributed to this study. The authors wish to give special thanks to the people who kindly agreed to participate. The authors are also indebted to Gabriela 
Díaz, a certified English translator graduated from our University for critically reading the manuscript.

This work was supported by the National Agency for Scientific and Technological Promotion (grants PICTO 2006 - 36035, PICT 2008 - 1814 and PICT 2012 - 1019) and the Science and Technology Department of the University of Córdoba (grants 361/16)

E. H. and V. L. D. carried out data collection, participated in the analysis of data and drafted the manuscript. L. R. A. and M. P. D. coordinated the procedures and revised critically the manuscript. A. R. O. and C. N. designed the study and contributed significantly in the discussion and the statistical analysis. All authors read and approved the final manuscript.

The authors declare that there are no conflicts of interest.

\section{References}

1. World Health Organization (2017) Cáncer (Cancer). http:// www.who.int/mediacentre/factsheets/fs297/es/ (accessed September 2017).

2. GLOBOCAN (2012) Estimated cancer mortality, all ages: both sexes. http://globocan.iarc.fr/old/summary_table_pop-html.asp? selection $=5032 \&$ title $=$ Argentina\&sex $=0 \&$ type $=1 \&$ window $=1 \&$ sort $=$ 0\&submit=\%C2\%A0Execute (accessed September 2017).

3. Ferlay J, Soerjomataram I, Ervik M, et al. (2013) GLOBOCAN 2012 v1.0, cancer incidence and mortality worldwide: IARC cancer base no. 11. http://globocan.iarc.fr (accessed August 2017).

4. Giovannucci E (2001) Insulin, insulin-like growth factors and colon cancer: a review of the evidence. J Nutr 131, 3109-3120.

5. Giovannucci E \& Michaud D (2007) The role of obesity and related metabolic disturbances in cancers of the colon, prostate, and pancreas. Gastroenterology 132, 2208-2225.

6. Kaaks R (2002) Nutrition, energy balance and colon cancer risk: the role of insulin and insulin-like growth factor-I. IARC Sci Publ 156, 289-293.

7. Sieri S, Muti P, Claudia A, et al. (2012) Prospective study on the role of glucose metabolism in breast cancer development. Int J Cancer 130, 921-929.

8. World Health Organization, Food and Agriculture Organization of the United Nations (1998) Carbohydrates in Human Nutrition. Report of a Joint FAO/WHO Expert Consultation, pp. 1-122. Rome: WHO.

9. Augustin LSA, Kendall CWC, Jenkins DJA, et al. (2015) Glycemic index, glycemic load and glycemic response: an International Scientific Consensus Summit from the International Carbohydrate Quality Consortium. Nutr Metab Cardiovasc Dis 25, 795-815.

10. Sieri S, Krogh V, Agnoli C, et al. (2015) Dietary glycemic index and glycemic load and risk of colorectal cancer: results from the EPIC-Italy study. Int J Cancer 136, 2923-2931.

11. Foster-Powell K, Holt SH \& Brand-Miller JC (2002) International table of glycemic index and glycemic load values. $\mathrm{Am}$ J Clin Nutr 76, 5-56.

12. Wolever TM (2008) Clasificaciónfisiológica de los hidratos de carbono de la dieta (The Glycaemic Index, A Physiological Classification of Dietary Carbohydrate), pp. 213-215. Zaragoza: ACRIBIA S.A.

13. Stoll BA (1999) Western nutrition and the insulin resistance syndrome: a link to breast cancer. Eur J Clin Nutr 53, 83-87.

14. Biddinger SB \& Ludwig DS (2005) The insulin-like growth factor axis: a potential link between glycemic index and cancer. Am J Clin Nutr 82, 277-278.
15. Liu Y, Tang W, Zhai L, et al. (2014) Meta-analysis: eating frequency and risk of colorectal cancer. Tumour Biol 35, 3617-3625.

16. Huang J, Fang $\mathrm{YJ}$, Xu M, et al. (2018) Carbohydrate, dietary glycaemic index and glycaemic load, and colorectal cancer risk: a case-control study in China. Br J Nutr 119 , 937-948.

17. Turati F, Galeone C, Gandini S, et al. (2015) High glycemic index and glycemic load are associated with moderately increased cancer risk. Mol Nutr Food Res 59, 1384-1394.

18. Choi Y, Giovanucci E \& Lee JE (2012) Glycaemic index and glycaemic load in relation to risk of diabetes-related cancers: a meta-analysis. Br J Nutr 108, 1934-1947.

19. Sieri S \& Krogh V (2017) Dietary glycemic index, glycemic load and cancer: an overview of the literature. Nutr Metab Cardiovasc Dis 27, 18-31.

20. Instituto Nacional de Estadísticas y Censos (National Institute of Statistics and Census) (2012) Censo Nacional de Población, Población, Hogares y Viviendas 2010: Censo del Bicentenario: Resultados definitivos Serie $\mathrm{B} \mathrm{N}^{\circ} 2$ (National Census of Population, Household and Housing 2010: Bicentennial Census: Final results Series B no. 2). Buenos Aires. http://www.censo 2010.indec.gov.ar (accessed May 2016).

21. World Medical Association (2013) World Medical Association Declaration of Helsinki: ethical principles for medical research involving human subjects. JAMA 310, 2191-2194.

22. Gottfried AW (1985) Measures of socioeconomic status in child development research: data and recommendations. Merrill-Palmer Quart 31, 85-92.

23. IPAQ Group (2012) International physical activity questionnaire. http://www.ipaq.ki.se/ipaq.htm (accessed August 2017).

24. Serón P, Muñoz S \& Lanas F (2010) Nivel de actividad física medida a través del cuestionario internacional de actividad física en población Chilena (Level of physical activity measured through the international physical activity questionnaire in the Chilean population). Rev Med Chile 138, 1232-1239.

25. Navarro A, Osella AR, Guerra V, et al. (2001) Reproducibility and validity of a food-frequency questionnaire in assessing dietary intakes and food habits in epidemiological cancer studies in Argentina. J Exp Clin Cancer Res 20, 365-370.

26. Navarro A, Cristaldo PE, Díaz MP, et al. (2000) Photographic Atlas for quantifying food and nutrient consumption in nutritional epidemiological studies in Córdoba, Argentina. Rev Fac Cienc Med Univ Nac Córdoba 57, 67-74.

27. Mazzei ME \& Puchulu MR (1993) Tabla de composición quimica de alimentos (Food Composition Table), p. 169. Buenos Aires: CENEXA.

28. Navarro A, Muñoz SE, Lantieri MJ, et al. (1997) Composition of saturated and unsaturated fatty acids of foods frequently consumed in Argentina. Arch Latinoam Nutr 47, 276-281.

29. Atkinson FS, Foster-Powell K \& Brand-Miller JC (2008) International tables of glycemic index and glycemic load. Diabetes Care 31, 2281-2283.

30. Rabe-Hesketh S \& Skrondal A (2008) Multilevel and Longitudinal Modeling Using Stata, 2nd ed. College Station, TX: Stata Press.

31. StataCorp (2017) Stata Statistical Software: Release 15. College Station, TX: StataCorp LLC.

32. Gonzalez-Segura I, Secchi DG, Carrica A, et al. (2014) Exfoliative cytology as a tool for monitoring premalignant and malignant lesions based on combined stains and morphometry techniques. J Oral Pathol Med 44, 178-184.

33. Rossi M, Lipworth L, Polesel J, et al. (2010) Dietary glycemic index and glycemic load and risk of pancreatic cancer: a casecontrol study. Ann Epidemiol 20, 460-465. 
34. Tasevska N, Jiao L, Cross AJ, et al. (2011) Sugars in diet and risk of cancer in the NIH-AARP Diet and Health Study. Int J Cancer 130, 159-169.

35. Qin B, Moorman PG, Alberg AJ, et al. (2016) Dietary carbohydrate intake, glycaemic load, glycaemic index and ovarian cancer risk in African-American women. Br J Nutr 115 , 694-702.

36. Zelenskiy S, Thompson CL, Tucker TC, et al. (2014) High dietary glycemic load is associated with increased risk of colon cancer. Nutr Cancer 66, 362-368.

37. Hu J, La Vecchia C, Augustin LS, et al. (2013) Glycemic index, glycemic load and cancer risk. Ann Oncol 24, 245-251.

38. Gnagnarella P, Gandini S, La Vecchia C, et al. (2008) Glycemic index, glycemic load, and cancer risk: a meta-analysis. $A m \mathrm{~J}$ Clin Nutr 87, 1793-1801.

39. Vulcan A, Manjer J \& Ohlsson B (2017) High blood glucose levels are associated with higher risk of colon cancer in men: a cohort study. BMC Cancer 17, 842.

40. Makarem N, Bandera EV, Lin Y, et al. (2017) Carbohydrate nutrition and risk of adiposity-related cancers: results from the Framingham Offspring cohort (1991-2013). Br J Nutr 117, 1603-1614.

41. Messina MJ (1999) Legumes and soybeans: overview of their nutritional profiles and health effects. Am J Clin Nutr $\mathbf{7 0}$, 439S-450S.

42. Aune D, Chan DS, Lau R, et al. (2012) Carbohydrates, glycemic index, glycemic load, and colorectal cancer risk: a systematic review and meta-analysis of cohort studies. Cancer Causes Control 23, 521-535.

43. Mulholland HG, Murray LJ, Cardwell CR, et al. (2009) Glycemic index, glycemic load, and risk of digestive tract neoplasms: a systematic review and meta-analysis. Am J Clin Nutr 89, 568-576.

44. Bao Y, Nimptsch K, Meyerhardt JA, et al. (2010) Dietary insulin load, dietary insulin index, and colorectal cancer. Cancer Epidemiol Biomarkers Prev 19, 3020-3026.

45. Flood A, Peters U, Jenkins DJ, et al. (2006) Carbohydrate, glycemic index, and glycemic load and colorectal adenomas in the Prostate, Lung, Colorectal, and Ovarian Screening Study. Am J Clin Nutr 84, 1184-1192.

46. Pou SA, Díaz M del P \& Osella AR (2012) Applying multilevel model to the relationship of dietary patterns and colorectal cancer: an ongoing case-control study in Córdoba, Argentina. Eur J Nutr 51, 755-764.

47. Wang Z, Uchida K, Ohnaka K, et al. (2014) Sugars, sucrose and colorectal cancer risk: the Fukuoka colorectal cancer study. Scan J Gastroenterol 49, 581-588.

48. Nagengast FM, Grubben MJ \& van Munster IP (1995) Role of bile acids in colorectal carcinogenesis. Eur J Cancer 31, 1067-1070.

49. Cheah PY (1990) Hypotheses for the etiology of colorectal cancer - an overview. Nutr Cancer 14, 5-13.

50. Perrigue MM, Kantor ED, Hastert TA, et al. (2013) Eating frequency and risk of colorectal cancer. Cancer Causes Control 24, 2107-2115.

51. Monnier L (2000) Is postprandial glucose a neglected cardiovascular risk factor in type 2 diabetes? Eur J Clin Invest $\mathbf{3 0}$, Suppl. 2, 3-11.

52. Rauber F, da Costa Louzada ML, Steele EM, et al. (2018) Ultraprocessed food consumption and chronic non-communicable diseases-related dietary nutrient profile in the UK (20082014). Nutrients 10, E587.

53. Silva FM, Giatti L, de Figueiredo RC, et al. (2018) Consumption of ultra-processed food and obesity: cross sectional results from the Brazilian Longitudinal Study of Adult Health (ELSABrasil) cohort (2008-2010). Public Health Nutr 21, 2271-2279.

54. Fardet A, Méjean C, Labouré H, et al. (2017) The degree of processing of foods which are most widely consumed by the French elderly population is associated with satiety and glycemic potentials and nutrient profiles. Food Funct 8, 651-658.

55. Buyken AE, Goletzke J, Joslowsky G, et al. (2014) Association between carbohydrate quality and inflammatory markers: systematic review of observational and interventional studies. Am J Clin Nutr 99, 813-833.

56. Du H, van der A DL, van Bakel MM, et al. (2008) Glycemic index and glycemic load in relation to food and nutrient intake and metabolic risk factors in a Dutch population. Am J Clin Nutr 87, 655-661.

57. Griffith JA, Ma Y, Chasan-Taber L, et al. (2008) Association between dietary glycemic index, glycemic load, and highsensitivity C-reactive protein. Nutrition 24, 401-406.

58. Levitan EB, Cook NR, Stampfer MJ, et al. (2008) Dietary glycemic index, dietary glycemic load, blood lipids, and C-reactive protein. Metabolism 57, 437-443.

59. Van Woudenbergh GJ, Kuijsten A, Sijbrands EJ, et al. (2011) Glycemic index and glycemic load and their association with C-reactive protein and incident type 2 diabetes. J Nutr Metab 2011, 623076.

60. Dickinson S, Hancock DP, Petocz P, et al. (2008) High glycemic index carbohydrate increases nuclear factor-kappa B activation in mononuclear cells of young, lean healthy subjects. Am J Clin Nutr 87, 1188-1193.

61. Ceriello A (2005) Postprandial hyperglycemia and diabetes complications: is it time to treat? Diabetes $\mathbf{5 4}, 1-7$.

62. Ardila J \& Gómez C (2001) Estudio de casos y controles (Cases and controls study). In Investigación clinica: epidemiología clínica aplicada (Clinical Research: Applied Clinical Epidemiology), pp. 168-185 [A Ruiz, C Gómez and D Londoño, editors]. Bogotá: CEJA.

63. Instituto Nacional de Estadísticas y Censos y el Ministerio de Salud de la Nación (National Institute of Statistics and Census and National Ministry of Health) (2013) $3^{\circ}$ Encuesta Nacional de Factores de Riesgo para enfermedades no transmisibles (3rd National Survey of Risk Factors for Non-Communicable Diseases). http://www.msal.gob.ar/images/stories/publicaciones/ pdf/11.09.2014-tercer-encuentro-nacional-factores-riesgo.pdf (accessed November 2018).

64. Becaria Coquet J, Tumas N, Osella AR, et al. (2016) Breast cancer and modifiable lifestyle factors in Argentinean women: addressing missing data in a case-control study. Asian Pac J Cancer Prev 17, 4567-4575.

65. Becaria Coquet J, Muñoz S \& Díaz MDP (2017) A framework to address potential bias in colorectal cancer: its implementation on a nutritional epidemiologic study in Argentina. Indian J Appl Res 7, 657-663.

66. Maldonado G \& Greenland S (2002) Estimating causal effects. Int J Epidemiol 31, 422-429. 